\title{
Transurethral Resection of the Prostate and Pre-Operative Anemia, in Men Older Than 60 Years
}

\author{
Nataša Nestorov, Ljiljana Gvozdenović, Mirka Lukić Šarkanović, \\ Goran Marušić, Teodora Božić \\ Clinical Center of Vojvodina, Novi Sad, University of medicine Novi Sad, Serbia \\ profgvozdenovic2010@hotmail.com
}

\begin{abstract}
:
Background/Aim: In their everyday clinical practice, anesthesiologists often deal with patients suffering from preoperative anaemia. The objective of the study was to determine the incidence and influence of preoperative anemia in the perioperative course in patients undergoing transurethral resection of the prostate.

Methods: The clinical study included 206 patients, who were divided into two groups. In the first group there were the patients with preoperative anemia (hemoglobin level less than $13 \mathrm{~g} / \mathrm{dL}$ ), and the control group with the patients without preoperative anemia (hemoglobin level $\geq 13 \mathrm{~g} / \mathrm{dL}$ ). The study was conducted at the Clinical Center of Vojvodina from June, 2011 to July, 2012. We analyzed the following: demographic factors, the ones related to the surgical procedure and the factors associated with anemia. Within the perioperative course we analyzed: the perioperative complications and the length of hospitalization.
\end{abstract}

Results: From the total of 206 patients, 54 (26.21\%) were the patients from the group with preoperative anemia (hemoglobin level $<13 \mathrm{~g} / \mathrm{dL}$ ), and the control group of $152(73.79 \%)$ patients without anemia (hemoglobin level $\geq 13 \mathrm{~g} / \mathrm{dL}$ ). The number of patients with perioperative complications was $15(27.78 \%)$ from the group with anemia and $22(14.47 \%)$ from the group without anemia. The complications were significantly more common in patients from the group with the preoperative anemia in comparison with the ones without anemia $(x 2=4.786$, $p<0.05)$. In the patients from the group with preoperative anemia, the average length of hospitalization was $6.44 \pm 3.489$ (5-29) days whereas in the patients from the control group it was $5.61 \pm 1.51$ (3-15) days. The patients from the group with anemia had significantly longer hospital stay, in comparison with the ones from the group without anemia $(t=2.386, p<0.05)$.

Conclusion: The incidence of preoperative anemia in our clinical study was $26.21 \%$. The examined patients with preoperative anemia had perioperative complications far more frequently and substantially longer hospital stay.

Keywords: prostate, surgery, anemia, perioperative course.

\section{INTRODUCTION}

In their everyday clinical practice, anaesthesiologists often deal with patients with pre-operative anemia that is manifested with lower hemoglobin levels. Its significance and influence on perioperative morbidity and mortality rates are the subject of numerous clinical studies (1-3). The anemia evaluation is especially important in elderly patients (over 65 years of age), in whom preoperative anemia is associated with increased morbidity and mortality, for this group of patients often suffers from cardiovascular, respiratory, cerebrovascular and other co-existing diseases (4-7). Several factors link the age of the patient and anemia as the risk factors for perioperative morbidity and mortality. The cardiac reserve in elderly patients is reduced (8), which can decrease the regular compensatory mechanisms due to lower hemoglobin levels $(9,10)$. Comorbidities, especially the coronary artery disease, in elderly patients reduce their tolerance to anemia (11). In addition, the preoperative anemia is quite significant for being a strong predictor variable for the transfusion of blood and its components (12-14). Transurethral resection of the prostate (TURP) is the second most common surgical procedure in men older than 65 years. The indications for surgical treatment are as follows: benign prostatic hyperplasia $(\mathrm{BPH})$ and prostate cancer, at an advanced stage, with urine retention, where palliative TURP, as a method of treatment, is applied. From the anesthesiologist's point of view, the specificity of the patients undergoing the transurethral resection of the prostate is that they are the elderly patients, most commonly the ones with multiple comorbidities, 
cardiovascular, respiratory and cerebrovascular ones, as well as the fact that the above mentioned interventions are most commonly associated with intraoperative and postoperative bleeding $(15,16)$.

We have decided to undertake the following clinical study, after taking into consideration the above mentioned specificities of the population undergoing the TURP treatment method and, due to the fact that there have been no published studies dealing with preoperative anemia in this particular group of patients recently.

The aim of this study was to determine the incidence and influence of preoperative anemia on perioperative course (perioperative complications and length of hospitalization) in patients undergoing transurethral resection of the prostate.

\section{MethodS}

A retrospective clinical study was conducted at the Clinic of Anesthesia and Intensive therapy and the Clinic of Urology of the Clinical Centre of Vojvodina, Novi Sad from $1^{\text {st }}$ June, 2011 to $30^{\text {th }}$ June, 2012. During the above mentioned period the total of 229 patients underwent a transurethral resection of the prostate. Due to the lack of the complete medical documentation, 23 (10.04\%) patients were excluded from the study. Therefore, 206 (89.96\%) patients with the complete medical documentation entered the study. The data were collected from the existing medical documentation (case history, anaesthesiological data, therapy lists, decursus, releasing forms). This study was approved by the Ethics Comittee of the Clinical Centre of Vojvodina.In the course of the clinical study, the following parameters were analyzed: 1) demographic factors, 2) surgical procedure related factors 3) anemail related factors and 4) within the perioperative course we analyzed the perioperatvne complications and the length of hospitalization. As for the demographic factors, the following ones were analyzed: the age of the patients, general health assessment according to the ASA classification (American Society of Anaesthesiologists, physical status class) (17), and comorbidities. As for the surgical procedure related factors, the following was analyzed: the main disorder as an indication for the TURP, the type of anaesthesia and surgical operation time. Further factors in relation to anaemail were analyzed: preoperative hemoglobin $(\mathrm{Hb})$ levels in blood, percentage decrease in the $\mathrm{Hb}$ level on postoperative day 1 (POD1-Hb change) which indicates the blood loss during the surgical procedure, the mean value of postoperative $\mathrm{Hb}$ until the postoperative day 3 and the blood transfusion administration quantity during the hospitalisation (18). The criteria for blood transfusion used at our institution was the transfusion trigger, $\mathrm{Hb} \leq 10 \mathrm{~g} / \mathrm{dL}$ (liberal transfusion strategy) (19). Within the perioperative course, the following was analyzed: perioperative complications (intraoperative and postoperative until the hospital release, new occurrence of perioperative outcomes), noted in the medical documentation and the length of hospitalization. The perioperative complications that were being examined were the following, systemic ones: cardiac, including ischemic cardiac complications (new occurrence of chest pain, electrocardiogram changes, or cardiac enzyme changes), myocardial infarction, dysrhythmias, or heart failures. Respiratory complications included pulmonary edema, tracheal re-intubation, pulmonary consolidation on the chest X-ray, or pleural effusion. Renal complications were defined as the serum creatinine elevation. Neurological complications were defined as the new occurrence of transient ischemic attack or stroke, delirium, or confusion. Infection required a documentation of the positive culture (20). Intrahospital mortality rate was analyzed, as well.

We defined preoperative anemia as a $\mathrm{Hb}$ level lower than $13 \mathrm{~g} / \mathrm{dL}$ in men according to the World Health Organization (21). Hb levels were measured within 30 days before the planned prostate surgical procedure. According to the preoperative $\mathrm{Hb}$ levels, the 206 examined patients were divided into two groups. 54 patients with preoperative anemia were in the first group (Hb level $<13 \mathrm{~g} / \mathrm{dL}$ ), whereas the control group consisted of 152 patients with no preoperative anemia ( $\mathrm{Hb}$ level $\geq 13 \mathrm{~g} / \mathrm{dL}$ ).

The examined patients were given general or regional anaesthesia depending on the general health of the patient. During statistical data processing, standard statistical research methods were used (descriptive statistics and frequency distribution). Numerical data were presented by medium arithmetic values and standard deviation, a comparison was done by the $\mathrm{t}-$ test. For the frequency of the observed parameters difference (distribution) hypotheses testing, $x^{2}$ test was used. Univariate and multivariate logistic regression analyses were perfomed to identify the risk factors influencing the perioperative course. A $p$ value of $<0.05$ was considered statistically significant. 


\section{RESULTS}

From the total of 206 patients included in the clinical study, 54 (26.21\%) ones had preoperative anemia (a group of patients with $\mathrm{Hb}<13 \mathrm{~g} / \mathrm{dL}$ ) and $152(73.79 \%)$ patients did not have preoperative anemia (a group of patients with $\mathrm{Hb} \geq 13 \mathrm{~g} / \mathrm{dL}$ ). The mean value of preoperative $\mathrm{Hb}$ in patients with anemia was $11.72 \pm 1.03 \mathrm{~g} / \mathrm{dL}$ and in the control group it amounted to $14.49 \pm 0.94 \mathrm{~g} / \mathrm{dL}$. Table 1 compares the demographic variables and the ones associated with surgical procedure among the patients with anemia and the ones without anemia. The average age of the patients was $71.12 \pm 8.35$ years. In comparison with the patients without anemia, the ones with anemia were significantly older $(\mathrm{t}=3.626, \mathrm{p}<0.01)$. As for the ASA status, there is a significantly larger number of ASA class 3 patients, in the group of patients with anemia, in comparison with the patients from the group without anemia $\left(x^{2}=10.690, p<0.05\right)$. The incidence of comorbidities in the examined patients was $81.1 \%$ and it was similar in both groups of patients $\left(x^{2}=1,699, p>0.05\right)$. As for the underlying disease, for the indication of the transurethral resection of the prostate, the patients from the group with anaemia had significantly more malignant prostate disease incidence than the ones from the group without anemia $\left(x^{2}=26,694, p<0.01\right)$. As for the type of anaesthesia and surgical operation time there was no significant difference between the groups (Table 1). Table 2 shows anemia associated factors. Transfusion was received by significantly more patients from the group with anemia in comparison with the ones without anemia $\left(\mathrm{x}^{2}=31.323, \mathrm{p}<0.01\right)$. There was no statistically significant difference in postoperative decrease in $\mathrm{Hb}$ values between the groups. As far as the mean value of postoperative $\mathrm{Hb}$ is concerned, significantly larger number of patients, from the group with anemia, had a postoperative $\mathrm{Hb}<13 \mathrm{~g} / \mathrm{dl}$ (postoperative anemia) in comparison with the ones without anemia (96.3\% vs $41.4 \%$ ). The number of patients who had perioperative complications was $15(27.78 \%)$ from the group with anemia $(\mathrm{Hb}<13 \mathrm{~g} / \mathrm{dL})$ and $22(14.47 \%)$ from the group without anemia $(\mathrm{Hb} \geq 13 \mathrm{~g} / \mathrm{dL})$. The complications were significantly more common in patients from the group with preoperative anemia in comparison with the ones from the group without anemia $\left(x^{2}=4.786, p<0.05\right)$.

Table1. Demografic factors and surgical procedure related factors

\begin{tabular}{|l|c|c|}
\hline \multicolumn{1}{|c|}{ General variables } & No anemia $(\mathbf{n = 1 5 2})$ & Anemia $(\mathbf{n}=\mathbf{5 4})$ \\
\hline Age (years), $\bar{X} \pm$ SD & $69,89 \pm 8,57$ & $74,56 \pm 6,65$ \\
\hline ASA class\%, $n(\%)$ & $65(42,8)$ & $10(18,5)$ \\
\hline $1-2$ & $85(55,9)$ & $42(77,8)$ \\
\hline 3 & $2(1,3)$ & $2(3,7)$ \\
\hline 4 & $120(78,9)$ & $47(87,0)$ \\
\hline Comorbidity, $\mathrm{n}(\%)$ & $32(21,1)$ & $7(13,0)$ \\
\hline Yes & \multicolumn{2}{|c|}{} \\
\hline No & $136(89,5)$ & $31(57,4)$ \\
\hline Main disorder, $\mathrm{n}(\%)$ & $16(10,5)$ & $23(42,6)$ \\
\hline BPH & \multicolumn{2}{|c|}{} \\
\hline Malignant tumor & $43(28,3)$ & $21(38,9)$ \\
\hline Type of anaesthesia, $\mathrm{n}(\%)$ & $109(71,7)$ & $33(61,1)$ \\
\hline General & $53,99 \pm 31,39$ & $60,28 \pm 21,33$ \\
\hline Regional &
\end{tabular}

n- number of patients; SD- standard deviation; ASA-American Society of Anaesthesiologists; * ASA scores: $1=$ healthy patient, $2=$ mild systemic disease but no functional limitations, $3=$ severe systemic disease with definite functional limitations, $4=$ severe systemic disease that is a constatnt threat to life, $5=$ moribund patient unlikely to survive $24 \mathrm{~h}$ with or without an operation; BPH-Benign Prostatic Hyperplasia;

Table2. Anemia associated factors

\begin{tabular}{|l|c|c|c|}
\hline \multicolumn{1}{|c|}{ Variable } & No anemia $(\mathbf{n = 1 5 2}) \mathbf{n ~ ( \% )}$ & Anemia (n=54) n (\%) & p value \\
\hline Perioperative transfusion, yes & $8(5,3)$ & $19(35,2)$ & 0,000 \\
\hline POD1- Hb change & \multicolumn{3}{|c|}{} \\
\hline Change $\leq 20 \%$ & $119(78,3)$ & $27(50)$ & 0,332 \\
\hline Change $>20 \%$ & $12(7,9)$ & $5(9,3)$ & \\
\hline Postoperative $\mathrm{Hb} \geq 13 \mathrm{~g} / \mathrm{dL}$ & $89(58,9)$ & $2(3,7)$ & 0,000 \\
\hline Postoperative $\mathrm{Hb}<13 \mathrm{~g} / \mathrm{dL}$ & $63(41,4)$ & $52(96,3)$ & \\
\hline
\end{tabular}

*POD1-Hb change - percentage drop in the Hb level on postoperative day 1; Hb-hemoglobin 
Table 3 shows the incidence of individual complications in relation to the total number of patients in both groups. The table shows that cardiac complications were the most common ones in both groups of patients. The patients from the group with anemia had significantly more cardiac complications in comparison with the ones from the group without anemia $\left(x^{2}=7.594, p<0.05\right)$.

Table3. The frequency of complications related to the total number of patients in both groups

\begin{tabular}{|c|c|c|}
\hline Complications & No anaemia $(n=152)$ & Anemia (n=54) \\
\hline Cardiac & $16(10,53)$ & $14(25,93)$ \\
\hline Respiratory & $2(1,32)$ & $1(1,85)$ \\
\hline Neurological & $2(1,32)$ & $1(1,85)$ \\
\hline Renal & $1(0,66)$ & $1(1,85)$ \\
\hline Infection & $4(2,63)$ & $0(0)$ \\
\hline Death & $1(0,66)$ & $0(0)$ \\
\hline $\begin{array}{l}\text { Total number of patients with } \\
\text { complications }\end{array}$ & $22(14,47)$ & $15(27,78)$ \\
\hline 0 Complication & $130(85,53)$ & $39(72,22)$ \\
\hline 1 Complication & $18(11,84)$ & $13(24,08)$ \\
\hline$\geq$ Complications & $4(2,63)$ & $2(3,70)$ \\
\hline
\end{tabular}

In the patients from the group with preoperative anemia, the average length of hospitalization was $6.44 \pm 3.489$ (5-29) days whereas in the patients from the control group it was $5.61 \pm 1.51(3-15)$ days. The patients from the group with anemia had significantly longer hospital stay, in comparison with the ones from the group without anemia $(\mathrm{t}=2.386, \mathrm{p}<0.05)$.

In order to compare the predictor parameters, the examined variables were tested by the logistic regression analysis where the dependent variable were the perioperative complications as well as the length of hospitalization (hospitalization longer than five days). The univariate logistic regression analysis included the following independent variables: the age of the patients, comorbidities, ASA status, preoperative $\mathrm{Hb}$, transfusion, $\mathrm{POD} 1-\mathrm{Hb}$ changes and postoperative $\mathrm{Hb}$. In addition, the multivariate logistic regression analysis included the variables associated with the perioperative complications as well as the length of hospitalization, according to the univariate analysis.

In Table 4 it is shown that there is a statistically significant univariate connection between the preoperative $\mathrm{Hb}<13 \mathrm{~g} / \mathrm{dL}$ and postoperative $\mathrm{Hb}<13 \mathrm{~g} / \mathrm{dL}$ with perioperative complications. According to the results of the multivariate regression analysis the postoperative $\mathrm{Hb}<13 \mathrm{~g} / \mathrm{dL}$ is an independent predictor of the perioperative complications incidence (Table 5). The patients who had the postoperative anemia had 2.5 times greater chance of perioperative complications incidence.

Table4. Univariate analysis of risk factors for perioperative complications

\begin{tabular}{|c|c|c|c|}
\hline Variable & Number & Complication $\mathbf{n}(\%)$ & p value \\
\hline Total number of patients & 206 & $37(17,96)$ & \\
\hline \multicolumn{4}{|l|}{ Age (years) } \\
\hline$<65$ & 41 & $5(12,1)$ & 0,366 \\
\hline$\geq 65$ & 165 & $32(19,4)$ & \\
\hline \multicolumn{4}{|l|}{ Comorbidity } \\
\hline Yes & 167 & $33(19,8)$ & 0,245 \\
\hline No & 39 & $4(10,3)$ & \\
\hline \multicolumn{4}{|l|}{ ASA class } \\
\hline$<3$ & 75 & $11(14,7)$ & 0,451 \\
\hline$\geq 3$ & 131 & $26(19,8)$ & \\
\hline \multicolumn{4}{|l|}{ Preoperative $\mathrm{Hb}$} \\
\hline$\langle 13 \mathrm{~g} / \mathrm{dL}$ & 54 & $15(27,8)$ & 0,038 \\
\hline$\geq 13 \mathrm{~g} / \mathrm{dL}$ & 152 & $22(14,5)$ & \\
\hline \multicolumn{4}{|l|}{ Perioperative transfusion } \\
\hline Yes & 27 & $8(29,6)$ & 0,107 \\
\hline No & 179 & $29(16,2)$ & \\
\hline \multicolumn{4}{|l|}{ POD1-Hb change ${ }^{*}$} \\
\hline Change $\leq 20 \%$ & 146 & $23(15,8)$ & 0,448 \\
\hline Change $>20 \%$ & 17 & $4(23,5)$ & \\
\hline \multicolumn{4}{|l|}{ Postoperative $\mathrm{Hb}$} \\
\hline$<13 \mathrm{~g} / \mathrm{dL}$ & 111 & $28(24,6)$ & 0,010 \\
\hline$\geq 13 \mathrm{~g} / \mathrm{dL}$ & 95 & $9(9,9)$ & \\
\hline
\end{tabular}

$n$ - number of patients; ASA-American Society of Anaesthesiologists; Hb- hemoglobin; "PODI-Hb change percentage drop in the Hb level on postoperative day 1 
Transurethral Resection of the Prostate and Pre-Operative Anemia, in Men Older Than 60 Years

Table5. Multivariate analysis of risk factors for perioperative complications

\begin{tabular}{|c|c|c|c|}
\hline Variable & p value & OR & 95\% CI \\
\hline Preoperative $\mathrm{Hb}<13 \mathrm{~g} / \mathrm{dL}$ & 0,384 & 1,451 & $0,628-3,352$ \\
\hline Postoperative $\mathrm{Hb}<13 \mathrm{~g} / \mathrm{dL}$ & 0,046 & 2,505 & $1,016-6,177$ \\
\hline
\end{tabular}

OR - Odds Ratio; CI - Confidence Interval; Hb-hemoglobin

In Table 6 it is shown that there is a statistically significant univariate connection between the preoperative $\mathrm{Hb}<13 \mathrm{~g} / \mathrm{dL}$, transfusion and postoperative $\mathrm{Hb}<13 \mathrm{~g} / \mathrm{dL}$ with the length of hospitalization. According to the results of the multivariate analysis, in predicting the length of hospitalization as the dependent variable, there is not any predictor that provides a unique, statistically significant, contribution to the model ( $\mathrm{p}>0.05$ ) (Table 7).

Table6. Univariate analysis of risk factors for the length of hospitalization

\begin{tabular}{|c|c|c|c|}
\hline Variable & Number & Length of stay $>5$ days $n(\%)$ & p value \\
\hline Total number of patients & 206 & $75(36,4)$ & \\
\hline \multicolumn{4}{|l|}{ Age (years) } \\
\hline$<65$ & 41 & $10(24,4)$ & 0,102 \\
\hline$\geq 65$ & 165 & $65(39,4)$ & \\
\hline \multicolumn{4}{|l|}{ Comorbidity } \\
\hline Yes & 167 & $61(36,5)$ & 1,000 \\
\hline No & 39 & $14(35,9)$ & \\
\hline \multicolumn{4}{|l|}{ ASA class } \\
\hline$<3$ & 75 & $25(33,3)$ & 0,548 \\
\hline$\geq 3$ & 131 & $50(38,2)$ & \\
\hline \multicolumn{4}{|l|}{ Preoperative $\mathrm{Hb}$} \\
\hline$<13 \mathrm{~g} / \mathrm{dL}$ & 54 & $27(50,0)$ & 0,021 \\
\hline$\geq 13 \mathrm{~g} / \mathrm{dL}$ & 152 & $48(31,6)$ & \\
\hline \multicolumn{4}{|l|}{ Perioperative transfusion } \\
\hline Yes & 27 & $16(59,3)$ & 0,010 \\
\hline No & 179 & $59(33,0)$ & \\
\hline \multicolumn{4}{|l|}{ POD1-Hb change } \\
\hline Change $\leq 20 \%$ & 146 & $47(32,2)$ & 0,279 \\
\hline Change $>20 \%$ & 17 & $8(47,1)$ & \\
\hline \multicolumn{4}{|l|}{ Postoperative $\mathrm{Hb}$} \\
\hline$<13 \mathrm{~g} / \mathrm{dL}$ & 111 & $49(43,0)$ & 0,041 \\
\hline$\geq 13 \mathrm{~g} / \mathrm{dL}$ & 95 & $26(28,6)$ & \\
\hline
\end{tabular}

n- number of patients; ASA-American Society of Anaesthesiologists; Hb-hemoglobin; POD1-Hb change percentage drop in the $\mathrm{Hb}$ level on postoperative day 1

Table7. Multivariate analysis of risk factors for the length of hospitalization

\begin{tabular}{|l|l|l|l|}
\hline \multicolumn{1}{|c|}{ Variable } & \multicolumn{1}{c|}{ p value } & \multicolumn{1}{c|}{ OR } & \multicolumn{1}{c|}{ 95\% CI } \\
\hline Preoperative $\mathrm{Hb}<13 \mathrm{~g} / \mathrm{dL}$ & 0,302 & 1,489 & $0,699-3,174$ \\
\hline Perioperative transfusion & 0,109 & 2,106 & $0,846-2,44$ \\
\hline Postoperative $\mathrm{Hb}<13 \mathrm{~g} / \mathrm{dL}$ & 0,430 & 1,320 & $0,622-2,634$ \\
\hline
\end{tabular}

OR - Odds Ratio; CI - Confidence Interval; Hb- hemoglobin

\section{DisCuSSION}

Our clinical study, that included the patients who underwent the transurethral resection of the prostate between June 2011 and July 2012 showed that the preoperative anemia was a relatively common state which is significantly in connection with the perioperative complications and the length of hospitalization. The prognostic value of preoperative anaemail in surgical procedures has been examined in many populations of the patients in both cardiac and non-cardiac surgery. In addition, numerous clinical studies, which included a relatively small number of patients who had undergone a particular type of surgical procedure have been conducted $(18,22)$. These examinations have shown that anemia is an independent risk factor for morbidity and mortality in surgical patients $(3,4,23)$, which is the reason why it should be considered a serious medical condition that can be treated (3).

In one of the biggest observational studies ( $W u$ et al.), which involved 310311 patients over 65 years who had undergone non-cardiac surgical procedure, it was concluded that $42.8 \%$ of them had preoperative anemia (4). According to the Beatlie et al. study, which involved 7679 patients over 18 years, who had also undergone non-cardiac surgical procedure, $39.8 \%$ of the men had preoperative 
anemia that was defined as $\mathrm{Hb}<13 \mathrm{~g} / \mathrm{dL}$ in men (1). The results of our study involving men undergone transurethral resection of the prostate, have shown that the frequency of preoperative anemia is a little lower in relation to other studies and it is $26.21 \%$, and is defined as $\mathrm{Hb}<13 \mathrm{~g} / \mathrm{dL}$ value.

$W u$ et al. demonstrate that preoperative anemia, even when discrepancies from physiological values of hematocrits are minimal, is linked to the increase in risk of postoperative mortalities and cardiac complications. The results of this study on a large sample of patients, mostly men older than 65 years, show that the increased cardiac complications and mortality risk is in proportion to the degree of anemia (4). Our study which included patients of similar demographic features also showed that patients with anemia had statistically significantly more cardiac complications in comparison with the group without anemia. As for the mortality rate in our study, there was one case of death in a patient who did not have anemia. The reason why our result is different in relation to other studies on mortality is likely due to the fact that we examined intra-hospital mortality rate only, and it is a small sample.

The study by Dunne et al., which involved patients of similar demographic features as ours, has examined the influence of preoperative anemia on the postoperative outcome in non-cardiac surgeries. It involved about 6301 patients, $95 \%$ of whom were men of the average age $61 \pm 13$ and the average ASA status of (2.6 \pm 0.7$)$. 33.9\% of them had preoperative anemia, anemic patients were administered five times as much blood in comparison to non-anemic ones (24). In our study preoperatively anemic patients received significantly more blood than the non anemic ones $\left(x^{2}=31.323, p<0.01\right)$. In the study by Dunne et al. it has been shown that the low preoperative hematocrit level and blood transfusion administration are significant independent predictors of the length of hospitalization (24). Our clinical study found that there is a statistically significant difference in the length of hospitalization between the preoperative anemic and non-anemic patients undergoing transurethral resection of the prostate. It is shown that there is a statistically significant univariate association between the preoperative $\mathrm{Hb}<13 \mathrm{~g} / \mathrm{dL}$, transfusion and the postoperative $\mathrm{Hb}<13 \mathrm{~g} / \mathrm{dL}$ in relation to the length of hospitalization.

The results of the Beattie et al. study, have shown that the proportion of blood administration is three times greater $(30.4 \%$ vs. $10.6 \%)$ in anemic patients than in the ones who had no preoperative anemia (1). In addition, the results of our examination tests are in accordance with the above mentioned ones. We showed that the blood transfusion was applied in $35.2 \%$ patients with preoperative anemia, in relation to the $5.3 \%$ of the ones who were not anemic prior to their surgical procedure.

However, there are several limitations of our clinical study that should be taken into consideration when interpreting the one. First, this is a retrospective clinical study. Furthermore, the fact that only intra-hospital morbidity and mortality rates were examined is also considered a disadvantage. Then, the fact that no intraoperative blood loss was recorded is also considered to be the shortage of our study. However, in the TURP, it is difficult to assess intraoperative blood loss due to the application of large amounts of irrigation fluid during the surgical procedure. For these reasons, in practice, it is found that frequent post-operative measurement of $\mathrm{Hb}$ would be a useful indicator of blood loss, which was used in our study, as well. Despite the above mentioned limitations the results of our study correspond to the results of the previous studies.

Considering the incidence of preoperative anemia and its influence on the perioperative course, which was established in the group of the examined patients, we believe that it is necessary to determine the values of hemoglobin at least 28 days before the scheduled surgery of the prostate, which would enable a timely anemia correction because the hemoglobin level determination is a rather simple and generally quite available test analysis, and anemail treatment is not expensive in many situations. Within a preoperative preparation, anemail etiology should be determined and its treatment should start before the scheduled surgical procedure (3). There are diverse therapeutic options depending on the etiology, such as iron therapy, erythropoietin therapy or autologous transfusion administration such is preoperative autologous blood donation $(3,25,26)$. This would significantly reduce perioperative complications and the length of hospitalization. So, perioperative alogenous blood transfusion administration that is by itself linked to numerous complications would be thus reduced $(26,27)$. Due to the limitations of our study, further prospective study in larger sample of patients is necessary. 


\section{Conclusion}

In our clinical study, the incidence of preoperative anemia was $26.21 \%$. The results of our study showed that the examined patients who had preoperative anemia had significantly more perioperative complications and increased length of hospitalization. The cardiovascular complications were the most common ones in both groups of patients.

\section{FUNDING}

No specific funding was received for this study.

\section{TRANSPARENCY DECLARATIONS}

Competing interests: none to declare

Transurethral resection of the prostate $=$ TURP

Benign prostatic hyperplasia $=\mathrm{BPH}$

American Society of Anaesthesiologists = ASA classification

Hemoglobin $=\mathrm{Hb}$

$\mathrm{Hb}$ level on postoperative day $1=\mathrm{POD} 1-\mathrm{Hb}$ change

\section{REFERENCES}

[1] Beattie WS, Karkouti K, Wijeysundera ND, Tait G. Risk associated with preoperative anemia in noncardiac surgery. Anesthesiology 2009; 110: 574-581.

[2] Goodnough LT, Nissenson AR, Dubois RW. Anemia: not justan innocent bystander? Arch Intern Med 2003; 163: 1400-1404.

[3] Goodnough LT, Maniatis A, Earnshaw P, Benoni G, Bevis P, Bisbe E, et al. Detection, evaluation and management of preoperative anemia in the elective orthopaedic surgical patient: NATA guidelines. Br J Anaesth 2011; 106: 13-22.

[4] Wu WC, Schifftner TL, Henderson WG, Eaton ChB, Poses RM, Uttley G, et al. Preoperative hematocrit levels and postoperative outcomes in older patients undergoing noncardiac surgery. JAMA 2007; 297: 2481-2488.

[5] Izaks GJ, Westendorp RG, Knook DL. The definition of anemia in older persons. JAMA 1999; 281: 1714-1717.

[6] Ania BJ, Suman VJ, Fairbanks VF, Rademacher DM, Melton LJ III. Incidence of anemia in older people: an epidemiologic study in a wll-defined population. J Am Geriatr Soc 1997; 45: 825-831.

[7] Jin F and Chung F. Minimizing perioperative adverse events in the elderly. Br J Anaesth 2001; 87: 608-624.

[8] Hees PS, Fleg JL, Mirza ZA, Ahmed S, Siu CO, Shapiro EP. Effects of normal aging on left ventricular lusitropic, inotrpic and chronotropic responses to dobutamine. J Am Coll Cardiol 2006; 47: 1440-1447.

[9] Duke M, Abelman W. The hemodynamic response to chronic anemia. Circulation 1969; 39: 503 515.

[10] Halm EA, Wang JJ, Boockvar K, Penrod J, Silberzweig SB, Magaziner J, et al. The effect of peroperative anemia on clinical and functional outcomes in patients with hip fracture. J Orthop Trauma 2004; 18: 369-374.

[11] Hubbard BL, Gibbons RJ, Lapeyre AC III, Zinsmeister AR, Clements IP. Identification of severe coronary artery disease using simple clinical parameters. Coron Artery Dis 1992; 152: 309-312.

[12] Myers E, O Grady P, Dolan AM. The influence of preclinical anemia on outcomes following total hip replacement. Arch Orthop Trauma Surg 2004; 124: 699-701.

[13] Shander A, Knight K, Thurer R, Adamson J, Spence R. Prevalence and outcomes of anemia in surgery: a systematic review of the literature. Am J Med 2004; 116(Issue 7): 58- 69.

[14] Gruson KI, Accousti KJ, Parsons BO, Pillai G, Flatow EL. Transfusion after shoulder arthroplasty: an analysis of rates and risk factors. J Shoulder Elbow Surg 2009; 18: 225-230. 
[15] Lynch M, Sriprasad S, Subramonian K, Thompson P. Postoperative haemorrhage following transurethral resection of the prostate and photoselective vaporization of the prostate. Ann R Coll Surg Engl 2010; 92: 555-558.

[16] Gempeler FE, Diaz L, Murcia PC. Evaluating coagulation in prostatectomy. Rev Col Anest 2009; 37: 202-211.

[17] Merchant R, Chartrand D, Dain S, Dobson G, Kurrek M, Lagace A et al. Guidelines to the practice of anaesthesia revised edition 2013. Can J Anaesth 2013; 60: 60-84.

[18] Jung DH, Lee HJ, Han DS, Suh YS, Kong SH, Lee KU et al. Impact of perioperative hemoglobin levels on postoperative outcomes in gastric cancer surgery. Gastric Cancer 2013; 16 : 377-382.

[19] Foss NB, Kristensen MT, Jensen PS, Palm H, Krasheninnikoff M and Kehlet H. The effects of liberal versus restrictive transfusion thresholds on ambulation after hip fracture surgery. Transfusion 2009; 49: 227-234.

[20] Leung JM and Dzankic S. Relative importance of preoperative health status versus intraoperative factors in predicting postoperative adverse outcomes in geriatric surgical patients. J Am Geriatr Soc 2001; 49: 1080-1085.

[21] WHO. Nutritional anaemias. Report of a WHO scientific group. Geneva: World Health Organization, 1968.

[22] Cladellas M, Bruguera J, Comin J, Vila J, Jaime E, Marti J et al. Is pre-operative anemia a risk marker for in-hospital mortality and morbidity after valve replacement? Eur Heart J 2006; 27 : 1093-1099.

[23] Musallam KM, Tamim HM, Richards T, Spahn DR, Rosendaal FR, Habbal A, et al. Preoperative anaemia and postoperative outcomes in non-cardiac surgery: a retrospective cohort study. Lancet 2011; 378: 1396-1407.

[24] Dunne JR, Malone D, Tracy JK, Gannon Ch, and Napolitano LM. Perioperative anemia: an independent risk factor for infection, mortality, and resource utilization in surgery. J Surg Res 2002; 102: 237-244.

[25] Goodnough LT, Shander A, Spivak JL, Waters JH, Friedman AJ, Carson JL, et al. Detection, evaluation and management of anemia in the elective surgical patient. Anesth Analg 2005; 101: 1858-1861.

[26] Gligorović V, Balint B, Čalija B. Osnovi kliničke transfuziologije. Urgentna i elektivna hemoterapija hemobioloških poremećaja. Beograd: Zavod za transfuziju krvi Srbije; 1996.

[27] Wu WC, Smith TS, Henderson WG, Eaton ChB, Poses RM, Uttley G, et al. Operative blood loss, blood transfusion, and 30-day mortality in older patients after major noncardiac surgery. Ann Surg 2010; 252: 11-17. 